\title{
MODERNIZATION OF THE BULGARIAN AIR FORCE AND INTEROPERABILITY WITH ALLIED FORCES ${ }^{1}$
}

\author{
Major-General Simeon SIMEONOV \\ Commander of the Bulgarian Air Force
}

\begin{abstract}
This article provides a brief introduction to the achievements of the Bulgarian Air Force. The author elaborates on the requirements, principles, and approaches for institutional development of the Air Force. The activities related to the implementation of the Bulgarian Air Force modernization projects and NATO interoperability are thoroughly presented.
\end{abstract}

Keywords: Air Force Transformation, Organizational Development, Technology Insertion.

The conclusions made as a result of the Strategic Defense Review, the missions and tasks of national defense predetermine the requirements towards the Air Force and the necessary resource framework for their realization. The operational capabilities encompass potential for accomplishing the Air Force main mission - to support the security and defense policy of the Republic of Bulgaria. Building and improving these capabilities depend on the following basic requirements:

- Information support;

- Command and control;

- Combat readiness;

- Deployment;

- Mission execution;

- Sustainability;

- Logistics support.

The new missions, tasks, and capability needs require transformation of the Air Force institutional structure and functional distribution, as well as building modern and effective units through realization of the following principles: joint effort; dependability; modular structure; functionality; and expeditionary nature. 
The basic approach to institutional building is the establishment of a comparatively small in numbers but capable Air Force, which would provide adequate contribution both to national defense and to the security of the Alliance. These would be achieved through:

- Command and Control system development;

- Gradual but continuous enlargement of the Air Force combat capability during the process of transformation till 2015;

- Development of projects and programs for acquiring new aviation equipment and modernization of part of the present aviation, radar, and ground based air defense (GBAD) equipment;

- Enhancing the level of sustainability;

- Development of the logistics support system.

The endorsed by the National Assembly of the "Long-term Vision for Development of the Armed Forces" envisages three periods for acquisition of new capabilities and transformation of the Bulgarian Air Force:

- First period-2005-2007;

- $\quad$ Second period - 2008-2010;

- Third period - 2011-2015.

In the context of these three periods, it is envisaged that the Bulgarian Air Force will conduct initiatives for transformation of its structures, life extension and modernization of existing equipment and rearmament with modern weapons and technology in order to achieve new capabilities.

The main initiatives for these periods are described below.

Reorganization of the Air Force Command and Control structure is scheduled for the first period; preparatory actions regarding the establishment of the Air Force Academy have already been undertaken. Projects for regeneration of the MiG-29 aircraft and modernization of the helicopters Mi-17 and Mi-24 are under way. The projects regarding rearmament with new types of aircraft for operational airlift and new types of tactical transport helicopters as well as combat search and rescue (SAR) have already been launched.

The second period includes reorganization of the main aviation and GBAD units, as well as the Air Force training system. The Air Force command and control system will be improved together with achievement of Air Defense system interoperability in accordance with the NATO Integrated Air Defense System (NATINADS). The process of modernization of a part of the aviation and SAM equipment continues in par- 
allel to the acquisition of new transport airplanes and helicopters. Projects for acquisition of a new multi-role fighter and 3D radars are about to begin.

The third period includes reorganization of the radar units and completion of the modernization, as well as discharge of surplus weapons and equipment. The Air Force Command and Control System is scheduled to become part of the new NATO Air Force Command and Control system (ACCS). The Air Force rearmament with new aircraft and radars will continue in this period. Certain quotas for personnel, technology, and arms are to be agreed.

The leadership of the Bulgarian Air Force definitely agrees that the most significant element and reason for the entire transformation of the Bulgarian Air Force is to accomplish the plans for modernization as related to approved levels of personnel numbers, insertion of advanced technologies and quantities of weapon systems. Modernization as a vital element of the transformation process requires allocation of considerable resources from the annual defense budgets.

Main national funds providing resources for modernization are:

- The National Defense budget;

- The long-term loans, guaranteed by the state.

Main foreign funds providing resources are:

- Funds from bilateral cooperation agreements;

- Participation in NATO programs (NSIP);

- Pre-accession instruments and EU funds.

The process of transformation and modernization require the inclusion of the national research and development potential with the objective to prepare and support the modernization projects. The basic principle for Air Force modernization is the rational use of the capacity of the national defense industry regarding international integration and cooperation as well as the establishment of strategic relations with foreign companies, in countries members of the European Union and NATO.

The main priority projects for modernization and rearmament of the Bulgarian Armed Forces have been determined by a decree of the Council of Ministers of the Republic of Bulgaria 46 dated May $27^{\text {th }}$, 2004.

The implementation procedures of these projects are organized in line with the Law on Public Tenders, the conditions and regulations for assigning special public contracts in the Instruction on Public Tenders, as well as the requirements and criteria for candidate assessment as approved by the Ministers of Economy, Finance, and Defense. 
Bulgarian Air Force HQ have planned, prepared and approved twenty-five projects for modernization and rearmament that are to be accomplished by 2015 . The most important projects are as follows:

1. "Recovery and Modernization of Mi-17s and Mi-24s" with the main objective of overhaul, extension of their life span, avionics modernization, interoperability in line with NATO and ICAO standards, communications and navigation equipment, and IFF system. The envisaged project results will enhance the operational capabilities and the accomplishment of respective force goals.

Regarding this project, a public tendering procedure for selection of a candidate was conducted and a contract with "Elbit Systems Ltd." was signed in December 2005. The contract started on January $1^{\text {st }}, 2006$.

2. "Procurement of New Utility Helicopters" with the intention of phased substitution of the existing transport helicopters and special helicopters for SAR operations, equipped with modern electronic suits and weapons in line with the NATO standards. The main objective of the project is to provide the whole range of equipment for freight, materials, troop-divisions transport, accomplishing tasks for combat SAR in peacetime, MEDEVAC, etc. The final results planned by the Bulgarian Air Force HQ include carrying out the agreements with NATO and the European Union. Within this project, the Ministry of Defense conducted procedures for selection of a candidate under the Law on the Public Tenders and, at the beginning of 2005, signed a contract with "Eurocopter-EADS." The contract was validated on January $1^{\text {st }}, 2006$.

3. The project "Procurement of New Multi-Role Fighters" will support the implementation of a wide range of tasks assigned to the Bulgarian Air Force, such as participation in allied operations and substitution of the obsolete fighters of Soviet design that are currently in use. We are in the process of preparation for launching the procedure.

4. The project "Procurement of New Transport Airplanes" provides for the implementation of the whole range of tasks regarding airlift, completion of sea patrol, SAR, MEDEVAC, and others. Concerning that project, a procedure for selection of a candidate has been conducted and a contract arranged with "Alenia Aeronautica," Italy; the signing of the contract is forthcoming.

5. The project for "Regeneration of MiG-29s" accomplishes the main operational requirements for the protection and defense of the airspace until new multipurpose fighters are acquired. With regard to that project, a selection 
procedure under the public tendering regulations has been conducted and a contract with the first selected candidate RSK MiG, Russia, has been prepared, the signing of which is to be concluded soon.

The above-mentioned projects are included in the list with eleven priority investment projects for modernization of the Bulgarian Armed Forces, approved with the decree of the Council of Ministers of the Republic of Bulgaria.

6. "Recovery \& Modernization of the $L-39$ s," including computer processing and information visualization, will allow the transition from L-39 ZA Training Combat aircraft to PC-9M (Pilatus) training aircraft and further to the future multipurpose fighters to be a smooth process in the overall modernization of the Bulgarian Air Force.

7. The project "Procurement of New Trainers" will meet the necessary requirements for propelled training aircraft for the needs of the young pilots from the Bulgarian Air Force.

8. The implementation of the project "Development of Air Surveillance, Air Traffic Control, and Air Defense Systems" will provide the complete range of missions and tasks for protection of the National Air Sovereignty in the allied defense system and full integration in NATINADS in line with the force goals. The project includes improvement of the system for air surveillance through introduction of 3D radars, capability for aircraft identification in accordance with the NATO STANAG 4193, improvement of the military air traffic control system and enhancement of the air defense system.

9. The main goal of the project "Modernization of GBAD SA-3" is enhancing the maneuverability and firing capabilities as well as the exploitation of the characteristics of SA-3, inclusion of the NATO identification "friend or foe" system, information visualization and provision of centralized control of SAM units in order to achieve interoperability with the NATO air defense standards and inclusion of the SA-3 units into NATINADS.

10. The project "Modernization of Bezmer and Dolna Mitropolia Air Bases" will provide communications, information and navigation interoperability of the airfields with aircraft equipped according to NATO and ICAO standards. The implementation of this project is underway.

11. The project "Modernization of CINS Battalions" aims at achieving interoperability of communications, information, and navigation aviation services and will provide the Chief Staff of the Air Force with opportunities for effective command and control of Air Force units. 
12. The implementation of the project "Establishment of CINS Modules in Accordance with the Accepted Force Goals" will facilitate the link with the NATO communications and information systems and inclusion of part of the CINS into the integrated information system as well as accomplishment of respective force goals through provision of equipment and software for:

- Protected UHF channels for voice and air-ground data conveyance;

- Protected communications channels for voice and data conveyance;

- Tactical Air Control Party;

- CINS for deployed aviation units;

- CINS modules for aviation units according to their alert status.

The main goal of the projects:

13. "Establishment of Bare Base and APOD Support Module" and

14. "NBC Reconnaissance Module"

is to provide the Bulgarian Air Force units assigned to allied NATO operations with technologies for nuclear and chemical reconnaissance, interoperable with NATO NBC units.

15. The project "Developing a Support-Jamming Pod" will increase the value of the aircraft, accomplishing tasks in a complex and hostile electromagnetic environment.

For each project, the Bulgarian Air Force HQ develops technical specifications, plan for realization, technical and economical analysis and proposals for direct offset. After being approved by the Defense Acquisition Council and the Defense Council, the Minister of Defense launches an open procedure for a public tender under the regulations for special public tenders.

In conclusion, I would like to emphasize that the Bulgarian Air Force is in a process of transformation of its doctrines, conceptual and regulatory documents, organizational and functional structure, personnel, weapons and technology, training and education, logistics support, military infrastructure and combat readiness, in order to be adequate to the dynamically changing defense environment and to establish modern Air Force, interoperable with allied air forces and capable to accomplish the whole range of missions and tasks in the frameworks of collective and national security. 


\section{Notes:}

1 This paper is based on a presentation by the Commander of the Bulgarian Air Force to the international conference organized by AFCEA-Varna, 14-15 March 2006, Park-Hotel "S.Peterburg" - Plovdiv.

SIMEON SIMEONOV - Information about the author is available on p. 18 of this volume. 